\title{
Just transitions in a public school food system: The case of Buffalo, N ew York
}

\author{
Special JAFSCD Issue \\ Local Government in Food Systems Work \\ Sponsored by \\ GROWING FOOD
CONNECTIONS
}

\author{
Jessica L. Gilbert, a* Alexandra E. Schindel, b and \\ Sarah A. Robert c \\ University at Buffalo (SUNY)
}

Submitted D ecember 15, 2017 / Revised February 23, April 19, and July 13, 2018 / Accepted August 9, 2018 /

Published online O ctober 17, 2018

Citation: Gilbert, J., Schindel, A. E., \& Robert, S. A. (2018). Just transitions in a public school food system: The case of Buffalo, New York. Journal of A griculture, Food Systems, and C ommunity D evelopment, 8(Suppl. 2), 95-113.

https:/ / doi.org/ 10.5304/ jafscd.2018.08B.011

Copyright (@ 2018 by the Authors. Published by the Lyson Center for Civic Agriculture and Food Systems. Open access under CC BY license.

\begin{abstract}
This article examines the public school food system in Buffalo, New York, for a just transition (Movement G eneration, n. d.). School food programs built on just transition characteristics democratize engagement, decentralize decisionmaking, diversify the economy, decrease consumption, and redistribute resources and power. The Buffalo public school district's food system is an important subsection of the city's food system that reaches the most vulnerable populations. School food systems contain teachable spaces within
\end{abstract}

a * Corresponding author: Jessica L. Gilbert, PhD candidate, D epartment of Geography, University at Buffalo (SUNY); 105 Wilkeson Quad; Buffalo, NY 14261 USA; jlgilber@ buffalo.edu

${ }^{b}$ Alexandra E. Schindel, Assistant Professor, D epartment of Learning and Instruction, University at Buffalo (SUNY); 564 Baldy Hall; Buffalo, NY 14260 USA; aedimick@ buffalo.edu

c Sarah A. Robert, Associate Professor, D epartment of Learning and Instruction, University at Buffalo (SUNY); 514 Baldy Hall; Buffalo, NY 14260 USA; saraharobert@ gmail.com schools to introduce students to healthy eating, fresh food, and the (in)equitable economies of the larger community food system. We argue that school food is an ideal entry point for introducing a just transition to the local food system, enhancing food equity built from healthier social, economic, ecological, and political systems. Related to this JAFSCD issue's call on Local Government in Food Systems Work, we aim to bring attention to the role and responsibility of public education systems in managing and enhancing community food systems through public policy. This qualitative case study examines five public school food programs

\section{Disclosures}

Gilbert works with Buffalo's food equity advocacy organizations and is a partner of the Good Food Buffalo Coalition, which is working to bring the Good Food Purchasing Program to BPS. Schindel is a parent of BPS students and works with teachers in BPS and throughout the U.S. as a participatory researcher examining social justice and civic engagement in science education. Robert is a BPS alumna and parent who works with teachers and parents to understand how to engage in more inclusive and just policy-making. 
in Buffalo, New York, for characteristics of a just transition using content analysis of policy and program documents. How does one public school food system engage in and build toward a just transition? Key findings include that all five programs analyzed reflected at least one characteristic of a just transition; programs lacked an emphasis on ecological justice; and younger generations must be included in the just transition implementation process. Ultimately, we argue that the school food system is ideally poised to initiate the implementation of a just transition.

\section{Keywords}

Community Food Systems, School Food, Just Transition, Food Equity, Ecological Sustainability, Social Justice

\section{Introduction}

The objective of this article is to examine the school food system in the Buffalo public school district (Buffalo Public Schools, or BPS) for elements of a just transition (Movement $G$ eneration, n.d.). A just transition is holistic in scope and emphasizes the following five activities for the well-being of a community: democratize engagement, decentralize decision-making, diversify economic activity, decrease consumption, and (re)distribute resources and power (Movement Generation, n.d.). How does a just transition occur within a school food system? We address this question through the case study of the public school food system in Buffalo, New York.

BPS's food system is an important subsection of the city's community food system (Raja, Hall, Norton, Gooch, Raj, Hawes, \& Whittaker, 2014), and has an important role in the community's larger soil-to-soil food system. Schools are sites of food procurement, preparation, consumption, and disposal, and, in some instances, schools are also sites of food production. The BPS district's food system is an important subsection of the city's food system that reaches the most vulnerable populations. School food systems also contain teachable spaces to introduce students to healthy eating, fresh food, and to the (in)equitable economies of the larger community food system. Related to this JAFSCD issue's call on Local Government in Food
Systems Work, we aim to bring attention to the role and responsibility of public education systems in managing and enhancing community food systems through public policy (Raja, Clark, Hodgson, \& Freedgood, 2017). Specifically, we examine school food policies and programs for evidence of and potential for a just transition in the school food system. We view a just transition as a nonlinear series of equitable and sustainable transformations that bring attention to, disrupt, and change hegemonic systems that oppress, dominate, and harm both people and the environment. O ur analysis is guided by the following question: How does one public school food system engage in and build toward a just transition?

To address this question, we begin by first putting forward a theory of a just transition. Afterward, we review the literature on school food systems linked to a broader discussion of food systems. Next is a description of the methodology and methods for this case study (Yin, 2003) of BPS's food system that applied content analysis (Kohlbacher, 2006; Reinharz, 1991). Based upon programs identified in a recent school food report (G ilbert, 2018b), we examine the following five food programs that offer food to students at schools: the National School Lunch and the School Breakfast programs, the BackPack Program, the School Pantry Program, the BPS Farm to School (F2S) initiative, and Buffalo School Gardens. O ur content analysis included developing a narrative description of each program and then analyzing each program for characteristics of a just transition. We argue that school food is an ideal entry point for introducing a just transition to the local food system, enhancing food justice and equity built from healthier social, economic, ecological, and political systems. Studies of states' school food and suggestions for improving it (Levine, 2010; Morgan \& Sonnino, 2008; Poppendieck, 2010; Ruis, 2017) are plentiful. The current study builds from this strong foundation with an analysis of and suggestions for how to improve the system holistically and equitably through a just transition framework.

\section{A Just Transition}

In this section, we begin with a brief history of the concept of a just transition. Then we shift to 
operationalizing the five key activities of a just transition: democratize engagement, decentralize decision-making, diversify economic activity, decrease consumption, and (re)distribute resources and power. This is followed by a general elaboration of the concept.

In the 1980s, the concept of a 'just transition' originated within U.S. trade union movements related to pollution regulations. Trade unions needed job creation during an energy transformation (e.g., from carbon-reliant to low-carbon energy transitions) (Healy \& Barry, 2017). The trade union movement focused on developing collaborative approaches to such transitions to advocate for workers' rights to quality jobs. The just transition concept then evolved from a concern for job creation in an emerging energy system to include justice for vulnerable communities affected by multiple interacting systems. Since the turn of the $21^{\text {st }}$ century, Movement $G$ eneration has evolved the just transition concept to call attention to the harm of an extractive economy and promote a transformation toward a regenerative economy. In this paper, we apply the current just transition framework elaborated by Movement Generation's struggle for healthy, just communities. While their framework includes food as one of the main pillars of an economy, we narrow our examination to the public school food system embedded within Buffalo's community food system and economy.

The aim of a just transition is to encourage action-oriented practices drawn from activist movements (e.g., Movement G eneration and trade unions). We identified five characteristics, or attributes, within the framework that we operationalize as tools for analyzing public school food programs. Although they are separated in our discussion to follow, in practice the characteristics interact and overlap. The first two activities involve decisionmaking. To begin, a just transition requires democratizing engagement by creating opportunities for equitable, collective deliberative processes. With this key attribute, process is emphasized. D ecisions are made through dialogue, and the analytic focus is on how decisions are made. Second, decentralizing decision-mak ing involves widening participation among multiple stakeholders in a food system. This occurs through the deliberate inclusion of multiple voices from communities and schools that have been historically underrepresented and marginalized in decision-making processes. D ecentralizing opens up the process of decision-making through shared authority across participants. "The concept of food democracy rests on the belief that every citizen has a contribution to make to the solution of our common problems" (Hassanein, 2003, p. 85). The analysis focuses on who is involved in decision making.

The next two attributes seek to redress economic injustices. The third characteristic diversifies economic activity to benefit multiple stakeholders through equitable sharing of resources, wealth, and power (Fraser, 1997). A just transition should involve a shift away from the industrial food system that commoditizes food and exploits employees and the environment. Instead of continued support for agri-business, a school food system can vary its sources of food, thus promoting food produced equitably with an emphasis on differentiated local economies. The fourth attribute involves decreasing consumption to reduce harmful ecological impacts of economic activity. Neither community food systems as a whole nor school food can be comprehensively improved without addressing both the social and ecological components.

The fifth and final attribute is (re)distributing resouroes and power, particularly to benefit the least advantaged and most vulnerable members of the food system. Redistribution in a just transition of school food systems involves awareness and action. Critical awareness of the diverse forms of injustices experienced by vulnerable student populations and economic, social, political, and ecological systems can and should lead to actions for change. Food system transitions embracing redistributional justice support equitable valuation, sharing, and distribution of both costs (i.e., negative consequences of environmental crises) and benefits for all members of society (Fraser, 1997). Just-transition practice and research should emerge from the lives and actions of communities most affected and most vulnerable to ecological, political, social, and economic stasis and change (Movement Generation, n.d.). This process should also concern access and choice to participate in food systems, regardless of income, nationality, location, etc. (Jenkins, 
McCauley, Heffron, Stephan, \& Rehner, 2016).

\section{Addressing Vulnerability}

Underpinning these five characteristics are theoretical foundations found in vulnerability studies and theories of justice. Multiple populations and systems - including economic, social, political, and ecological - interact and are susceptible to stress and injustice, thus creating and intensifying vulnerability (Eakin \& Luers, 2006). Public school food systems serve multiple populations, some of whom are marginalized through intersecting systems of oppression (e.g., racial, economic, gender and sexuality), thus increasing the vulnerability of these populations. Vulnerability "is socially constructed and is magnified by past and present injustices in communities with histories of domination or who have been denied access to power, resources, or participation in decision-making processes" (Miller Hesed \& O stergren, 2017, p. 186). When analyzed, vulnerability illustrates how the communities who have been least responsible for inequities within systems are also positioned to bear the brunt of any negative impacts of transitions. Vulnerability research also produces supportive responses that contribute to strengthening the resiliency of affected communities (Eakin \& Luers, 2006). School food research applying a just transition would not only illuminate the intersecting and historical legacies of oppression, but also include marginalized communities in producing responses for building a more equitable school food system.

Examining a school food system in relation to a just transition framework is useful for not only identifying vulnerabilities to humans and the environment but, as discussed above, identifying spaces for actions of transformation toward social justice. For example, if democratic participation in decision-making is successfully implemented into the school food system, food procurement, choices, disposal, and labor may be decentralized, and the economic system that undermines social justice is critiqued and transformed (Morgan \& Sonnino, 2013). The number of options for healthy, locally sourced food may increase, while the amount of preprocessed food served and waste produced is reduced. Simultaneously, the local purchases support the local economy as more food workers and producers are integrated into the system. An increase in the consumption of fresh food decreases the use of natural resources needed for food processing and packaging, as well as how far it has to be shipped. Such reshaping of the school food system may contribute to a redistribution of resources (healthy food more readily available to all, local producers supported) and power (industrial food producers and processors no longer monopolize school food), thus guiding school food through a socially and ecologically just transition.

\section{Literature Review}

E quity and Justiœ in Community F ood Systems To assess accurately how school food can encompass elements of a just transition, school food must be understood as nested within a larger community food system. As Guthman (2011) argues, foodrelated studies should consider the soil-to-soil process from production to disposal, as well as actors, policies, events, and outcomes both directly and indirectly involved in or impacted by food. A food systems approach is valuable because it integrates issues that may not immediately appear to be connected to food, such as community health, collective decision-making, social justice, and ecological sustainability, as well as taking into account past, present, and future events (Levkoe, 2011). Additionally, examining school food as a system-within-a-system highlights the numerous geographic scales that are connected throughout the various processes involved in food production, consumption, and waste disposal. It is critical to recognize the embedded interscalar power structures of the food system (Ericksen et al., 2012). The transition envisioned in this article identifies and shifts away from disadvantages incurred from the school food system by highlighting the politics that produce inequality and the strategies needed to move the system toward food justice (Gottlieb \& Joshi, 2010). The present study encourages a reconceptualization of the issues and vulnerabilities within a school food system and their associated solutions, such that new strategies may be discovered (Levkoe, 2011). 
Perhaps one of the most important insights provided by a food systems approach is the interconnectedness of society and the environment (Morgan \&Sonnino, 2013). As such, reconceptualizing food as a system emphasizes that solutions addressing food-related issues and vulnerabilities must target both societal and ecological harms. Humans are intricately connected to the world's nonhuman entities, and it is critical to assess food as a process that both is dependent on, and affects, "earth others" (G ibson-G raham \& Miller, 2015). Over the past 50 years the food system has undergone widespread industrialization, which has caused extensive degradation to the environmental resources upon which it depends (Ericksen et al., 2012). Unsustainable production methods of industrial agriculture are responsible for decreasing biodiversity, increasing erosion from soil runoff, depleting key soil nutrients, and polluting the soil, water, and air from chemical fertilizers and mechanized farming techniques. Consequently, increasing food production levels has come at the expense of environmental resources (Ericksen et al., 2012). In other words, humans are destroying the "earth others" upon which they rely; current production rates and methods cannot be sustained long-term for the school food system.

A food systems approach for a school food system illustrates the ways in which dominant agricultural practices exacerbate current and future food-related social injustices. If these production methods are maintained, the depletion of resources needed for agriculture will cause food production rates to drop, causing the availability of impacted food items to decrease and their prices to rise (Ericksen et al., 2012). Many low- and moderateincome populations cannot afford rising food prices, and inequity within the food system will be further exacerbated (Ericksen et al., 2012). This example demonstrates the interconnected nature of social and environmental components within the food system, which together necessitate a shift from destructive industrial to pro-environmental agricultural practices. In other words, any injustice, exploitation, or other harm instilled through the food system affects the entirety of the social and ecological community. Similarly, efforts to transition the food system toward equity - or justice- will improve conditions for both humans and nonhumans.

Furthermore, an examination of food as a system reveals that the aforementioned social and ecological injustices perpetuated by current industrial food production methods exacerbate distributional injustices. The tenets of distributional justice hold that lack of access, control, and the ability to choose whether and how to participate in the food system are additional sources of social injustice, and are particularly visible in urban lowand moderate-income communities (Fraser, 1997). Specifically, many vulnerable communities lack access to affordable, nutritious, and culturally appropriate food; thus, they often face food insecurity, defined as "a situation that exists when people lack secure access to sufficient amounts of safe and nutritious food for normal growth and development and an active and healthy life" (Food and Agriculture O rganization of the United Nations, International Fund for Agricultural D evelopment, \& World Food Programme, 2015). Y et a food systems approach reveals that simply increasing access to healthy, affordable food cannot provide a solution to food insecurity; instead, the underlying systemic causes must be addressed (Morgan \&Sonnino, 2013). Simply striving to achieve food security would not target all injustices throughout the food system, but rather would focus solely on improving physical, social, and economic access to nutritious food for people. Recognizing both the benefits and deficiencies of striving for food security, some scholars have drawn attention to food equity to ensure that "food systems are democratically controlled and community stakeholders can determine the policies that influence their food system," and that "all community members are able to grow, procure, barter, trade, sell, dispose, and understand the sources of food in a manner that prioritizes culture, equitable access to land, fair and equitable prices and wages, human health, and ecological sustainability" (Food Equity Ideas Lab Workshop Steering Committee, 2017, pp. 3-4). Food justice for public school students and their families requires acting in and on the current food system; bringing into focus equity and disparities from the perspectives of the most vulnerable; and linking to a broader 
social justice movement (G ottlieb \& Joshi, 2010). Achieving food equity and justice requires challenging the current power structures of the food system that emphasize profit and normalize injustice, and advocating for the implementation of a participatory system of governance that values community and well-being.

School F ood: A System N ested in a Community Food System

School food systems are nested within larger community food systems and are composed of integrated and interdependent human and nonhuman components. Therefore, in order to comprehensively improve school food, efforts must account for both the social and the ecological as interrelated parts of communities (Gilbert, 2018b). For this study, we focus on the school food system with its own underlying causal factors of socio-environmental inequity toward producing school food initiatives that tackle the needs and desires of students (Block, Chávez, Allen, \& Ramirez, 2012). Adapting Healy and Barry's (2017) suggestions, this requires a focus on politics and the political economy of feeding children. Feeding children at school involves politics or the engagement of communities and corporations with the state over struggles for finite symbolic and material resources (Robert \& Weaver-Hightower, 2011). Extensive studies of United States' school food have explored beneath the surface of decision-making regarding procurement (Morgan \& Sonnino, 2008), provisioning (Poppendieck, 2010), the nature of the program as an antipoverty, welfare program (Levine, 2010), and the balancing act between competing stakeholders (Ruis, 2017) to reveal a struggle for power over school food. Often times, power struggles have unintended consequences for the health and educational well-being of the children who consume school food and exclude them from potential improvement.

Globally, the health and educational implications of feeding school-aged children are well documented (Bundy, Burbano, Grosh, Gelli, Jukes, \& D rake 2009; Faught, Williams, Willows, Asbridge, \& Veugelers, 2017; World Food Program, 2017). Healthy food supports children's development emotionally and physically, encourages attendance, and fosters their ability to learn while at school (e.g., Cooper, Bandelow, \& Nevill, 2011; Florence, A sbridge, \& Veugelers, 2008; Meyers, Sampson, Weitzman, Rogers, \& Kayne, 1989; Murphy, Pagano, Nachmani, Sperling, Kane, \& Kleinman, 1998; Wesnes, Pincock, Richardson, Helm, \& Hails, 2003). However, school food systems affect more than individual "human capital." Like Poppendieck (2010), we argue that the current state of U.S. school food policy leaves the most vulnerable even more so. School food programs are avenues for justice for children and have the potential to affect communities more broadly through social, political, economic, and ecological transformations. The current study utilizes a just transition framework to illustrate how the school food system can be transformed in order to bring about socio-ecological justice at both the individual and systemic levels.

\section{Research Design and Methods}

This is a case study that qualitatively examines the BPS food system for five characteristics of a just transition. Case study research aims to "define research topics broadly and not narrowly, cover contextual or complex multivariate conditions and not just isolated variables, and rely on multiple and not singular sources of evidence" (Yin, 2003, p. xi). O ur examination of a public school food system must account for the historical and contemporary manifestations of, in this case, Buffalo's economic, social, and environmental conditions, all of which are embedded, or come to roost, within public schools. Thus, we first frame our case within an overview of the city of Buffalo in which the BPS food system is situated to illuminate the complex, multivariate conditions that affect the school food system, creating constraints to and opportunities for a just transition. The case study is explanatory in nature, with the findings revealing why the programs reflect (or do not) characteristics of a just transition and how the programs move toward just transitions (or do not).

We collected documents and conducted content analysis (Kohlbacher, 2006) as a means of interpreting qualitatively the school food system's policies and programs as a "specific, complex, functioning thing" (Stake, 1995, p. 2). Specifically, 
we focus our analysis on five programs identified on publicly accessible websites and through the authors' participation in the school food system: the National School Lunch and the School Breakfast programs, the BackPack Program, the School Pantry Program, the BPS Farm to School (F2S) initiative, and Buffalo School Gardens. While there are numerous food-related programs associated with BPS, we selected these five because they are formal programs that directly provide food to students at schools. There are other food transactions in schools and classrooms; for example, many elementary teachers provide food to students. However, we limit the case study to formal programs sanctioned by the district.

Data include primary and secondary documents relevant to the five programs: policy texts and secondary literature or interpretations of the policies such as program descriptions, procedures, public promotional material, and videos. In fall 2017, we downloaded, or saved via screenshots, documents from the BPS website, the Buffalo School Garden website, and Food Bank of Western New Y ork (WNY) website. ${ }^{1}$ In some instances this required following links to federal government pages or to program sponsors' materials. Each program is a piece of the school food system representing to the general public (Levkoe \& Wakefield, 2011) how the school food system works, how decisions are made, who is included or involved, and how the system is funded and in turn funds food producers.

O ur case study draws upon evidence from content analysis of documents (Kohlbacher, 2006; Krippendorff, 2013; Reinharz, 1991; Reinharz \& D avidman, 1992) and, at times on each of the author's practical experiences as participatoryaction researchers ${ }^{2}$ within the BPS community (Akom, 2011). O ur first step in analyzing the material downloaded was to develop a descriptive narrative that responds to a simple- though not simplistic-critical inquiry: who feeds whom what, how, when, and for what purpose? (Robert \& WeaverHightower, 2011). We also read the data for the five just transition strategies, formulated into questions: D oes the program democratize engagement? D ecentralize decision-mak ing? D iversity economic activity? D ecrease consumption? Redistribute resources and power?

The findings (the descriptive narrative and Table 1) and their discussion are woven together in the pages that follow. The overarching research question, restated from the beginning of the paper is: How does one public school food system engage in and build toward a just transition? The researchers read the data independently for explicit and implicit reference to each of the five characteristics. We then compared our coding to assess overall inter-rater reliability.

We verified our program and document selection and the content analysis through informal communication with members of the BPS food system. This was not in an effort to expand the scope of inquiry or data collection for this article; rather, it was to clarify that the programs analyzed in the following pages included as many of the formal food programs within the BPS food system as possible during the 2017-2018 school year and to verify the analysis as reflecting the nature of each program.

\section{Buffalo Public Schools: A Case Study of Just T ransitions}

\section{Buffalo Past and Present}

The BPS food system is nested within the historical and contemporary political, social, economic, and ecological systems of the city. D eindustrialization and harsh winters have long given Buffalo, New York, a bleak reputation for snow and rust. O ften referred to as "The City of No Illusions," Buffalo has one of the U.S.'s highest concentrations of urban poverty, intense racial segregation, obesity alongside hunger, lack of access to affordable, healthy food, Superfund-level contamination sites, and diminishing rural landscapes (primarily farmland) surrounding the city due to urban sprawl (Connelly, 2008; Krolikowski \& Magavern, 2017; Magavern, 2016; Raja et al., 2014). Additionally,

1 BPS Food Services D epartment website: http:/ / www.schoolnutritionandfitness.com/ index.php?sid=0603142256068325; Buffalo School Garden website: http:/ / www.buffaloschoolgardens.com/; Food Bank of WNY website: https:/ www.foodbankwny.org/ 2 See the Disclosures section on the first page of this article. 
Buffalo is a refugee resettlement city for a multitude of communities fleeing " . . . situations of strife such as war, persecution or natural disaster in their home countries" (Partnership for the Public Good, 2018a, p. 1). The top five countries represented by the newest Buffalonians are Burma, Bhutan, Somalia, Iraq, and the D emocratic Republic of Congo (Partnership for the Public Good, 2018a).

Youth struggle in the city. The youth poverty rate in Buffalo is the third highest among large cities nationally, surpassed only by D etroit and Cleveland. A majority (53.9\%) of children and youth under 18 live below the poverty line (Partnership for the Public G ood, 2018b). Challenges are not consistent across all races and ethnicities. Buffalo is the sixth most segregated city in the United States: 9\% of Buffalo's white residents live below the poverty line compared to $37 \%$ of both black and Hispanic residents. The median income for whites is US\$55,000, but is only US\$25,000 for blacks and US\$27,000 for Hispanics (Magavern, 2016).

Finally, the placement of supermarkets as well as other healthy food outlets follow the city's segregation patterns (Raja, Ma, \& Yadav, 2008). In racial- and ethnic-minority neighborhoods, corner stores and fast-food restaurants are the main sources of food, and access to fresh and healthy food is dependent upon motorized transportation. Most residents cannot afford a car and must instead rely on a shrinking and unreliable public transportation system (K rolikowski \& Magavern, 2017). Public transit serves more to deter, rather than assist, residents from traveling to supermarkets. Lack of access to nearby healthy food outlets or to dependable transit is a key contributor to the high rates of food insecurity in many neighborhoods. In addition, chronic diseases are prevalent; one in five children is obese (Erie County D epartment of Health, 2017). The public school food system is in a position to confront the health and well-being of the city's children.

Alongside these challenges, a renaissance is occurring in Buffalo. Renewed interest by developers in accumulating urban land and the capital and power of economic development agencies are reshaping the city. The Buffalo Billion, a statewide program launched by G overnor Andrew Cuomo, is planned to pump capital into the urban environment to address a multigenerational stagnant economy (Buffalo Billion, n.d.). Change is visible: new buildings, formerly abandoned buildings remodeled and inhabited, construction cranes, and more people in the downtown area and adjacent neighborhoods. However, changes are not occurring evenly throughout the city. Some neighborhoods are experiencing high rates of transformation, while others continue to see divestment or gentrification (Krolikowski \& Magavern, 2017). Such disparate patterns are evident in the local food system: the number of community supported agriculture (CSA) operations, farmers markets, restaurants, and outlets such as locally owned cooperatives and grocery stores selling organic products is growing in some neighborhoods but leaving out others.

Buffalo is at a historic moment. Its renaissance can move toward or away from a just transition that emphasizes a regenerative economy based on cooperation, democratic participation in decisionmaking, and ecological and social well-being. It is against this backdrop we examine the role of the BPS district in cultivating a just transition.

\section{Buffalo Public School F ood System: E mergence of a Just Transition} BPS enrolls about 34,000 students. The district has 37 elementary schools, eight middle schools, and 27 high schools. BPS operates a "school choice" system in which students are bussed to every corner of the city. A majority of Buffalo's students eat two free meals a day at school; of the 34,000 students enrolled during the 2017-2018 school year, 24,000 ate breakfast and 27,000 ate lunch. School meals serve as a significant food source for BPS students (Food Bank of WNY, n.d.), which motivates stakeholders both within and outside of BPS to aim for the provision of healthy and nutritious school food. However, due to budgetary restraints, lack of staff training, and limitations of available cooking facilities, most food served to students is preprocessed and reheated (G ilbert, 2018b). As the amount and quality of food consumed directly affects students' academic performance (Bundy et al., 2009; Faught, Williams, 
Willows, A sbridge, \& Veugelers, 2017), improvements in school food have the potential to minimize disadvantages. Compared to students from economically stable families, students from low- and moderate-income families often rely on school food for both breakfast and lunch, and, in the most severe cases, take food home for dinner (Gilbert, 2018b). Due to the high percentage of students living in poverty, the quality of school food served by BPS remains not only a nutritional concern but a social justice concern as well. School food programs have taken steps to improve the quality of food served at BPS, but the potential for improvement is constrained by federal budgeting and guidelines for school food (Nutrition Standards, 2012).

BPS food and nutrition committee

A key element of just transitions is the emergence of new governance arrangements. In BPS, a new arrangement has emerged in the form of the BPS Food and Nutrition Committee. This is a partnership of stakeholders, individuals, and organizations from both within BPS and throughout the city working to improve school food. It is led by two individuals: a parent and the director of child nutrition services at BPS.

Much of their work aligns closely with the social values of a just transition. The committee aims to address the social injustices caused by the quality of BPS's school food. For example, this committee played a leading role in enhancing the decentralization and redistribution of resources and power throughout the school food system with the implementation of the F2S initiative. They continue to encourage expanded healthy food choices for students in the district's vending machines. There is also a strong emphasis on youth involvement to ensure that students' concerns are addressed.

As with most initiatives to improve BPS's school food system, the committee has experienced varying levels of success with initiatives. While they have faced numerous barriers, including funding, policy, and participation constraints, one of the primary reasons that they have been unable to contribute to a comprehensive improvement of school food is that they do not address the ecological injustices within the school food system. Y et, due to their emphasis on reducing preprocessed foods and increasing the role of the F2S program at BPS, the committee has the potential to play a significant role in mitigating the negative environmental impacts of school food, further contributing to a just transition at BPS.

Multiple school-based food initiatives The BPS Food Services D epartment implements or coordinates with the following programs: the National School Lunch and the School Breakfast programs, the BackPack Program, the School Pantry Program, the BPS F2S initiative, and Buffalo School Gardens. These programs exhibit some, but not all, elements of a just transition as illustrated in Table 1. O ur assignment of "yes" and/ or "no" reflect both whether the program reflects the strategy already or whether there is a potential movement toward meeting the strategy identified in the data. Below the table, we provide a narrative of each program.

Traditional programs: $\mathrm{N}$ ational School Break fast and L unch Programs

Due to the high level of poverty in the city, all BPS students can eat free school breakfasts and lunches through the Community Eligibility Provision of the federal school meal program. There were 34,000 BPS students in the 2017-2018 school year, and daily the schools provide 24,000 children with breakfast; 27,000 children with lunch; and, 7,000 children with a cold or hot supper. The district participates in the National School Lunch and School Breakfast programs, which cover meal costs in the highest-poverty schools and districts in the nation (Nutrition Standards, 2012). The School Breakfast and National School Lunch programs are federally funded but locally administered and represent a significant input of food to the school food system. Thus it is a quasilocal program, dependent on federal resources and guidelines that govern purchasing and serving of food. Importantly, meals are only eligible for reimbursement by this program if they adhere to USD A nutritional regulations, which limits schools' and students' choice in food consumption (Nutrition Standards, 2012).

The School Breakfast and National School 
Journal of Agriculture, Food Systems, and Community Development ISSN: 2152-0801 online https:/ / www.foodsystemsjournal.org

Table 1. Buffalo Public School Food System

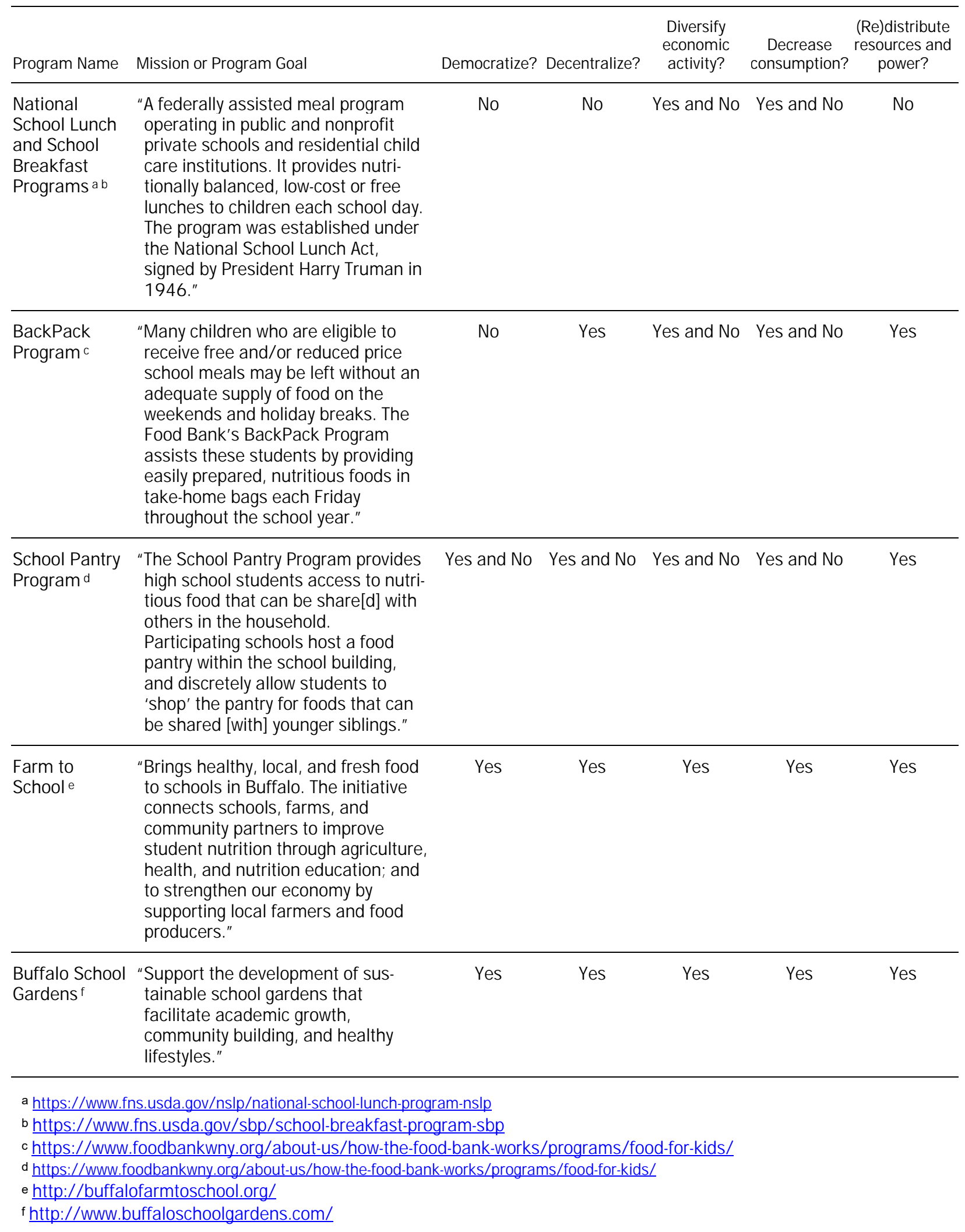


Lunch programs have a complicated relationship with the community food system and with the just transition framework. The fact that it is a quasilocal program, dependent on federal guidelines for purchasing funds, complicates the democratizing and decentralizing that the program could accomplish. On the one hand, the program provides an aspect of equity through education by providing free food for all students. On the other hand, procurement and menu selections are, for the most part, centralized activities, which limits the democratic engagement of students and staff in school food-related decision-making. BPS menus mention by brand certain cereals and breakfast treats, such as Cocoa Puffs $^{\mathrm{TM}}$ or French Toast Cunchmania ${ }^{\mathrm{TM}}$. Naming brands illustrates the stability of the current commodity chain represented by the centralized National School Lunch and School Breakfast programs' purchasing, which demonstrates a lack of opportunities for democratic engagement.

Further, in the case of Buffalo, with a large population of refugee students, centralized decision-making also reduces the possibilities for providing culturally relevant meals. For example, the student bodies in many BPS schools are predominantly refugee populations who prefer rice rather than pasta, or who are vegetarian but do not eat peanut butter (the standard vegetarian option). BPS's diverse student population would benefit immensely if individual schools were able to create their own menus rather than adhere to the districtwide menu. Therefore, while acknowledging the rationale for the centralized nutritional guidelines and menu options, implementing the same menu districtwide heavily constrains opportunities for decentralized decision-making.

The potential for disrupting the market economic transactions of the school food system is mixed. The federal funds and guidelines for purchasing are constraining. For example, BPS receives almost US\$1 million of free food per year from federal school food reimbursement programs (Gilbert, 2018a). As the district works to maximize the food it is able to procure from these programs, it is limited in its ability to incorporate geographic preference (Gilbert, 2018b). As such, it can be difficult for school districts to purchase more than a small portion of their food from fresh and local sources (G ilbert, 2018b). The National School Lunch and School Breakfast programs provide few allowances to decrease the purchase and consumption of preprocessed foods and the negative social and ecological impacts resulting from their consumption. Based on our analysis, the potential of the National School Lunch and School Breakfast programs to contribute to a just transition is quite constrained.

E volving programs: School Back Pack and Pantry Programs Take-home food is provided to students for weekends and holidays through the Food Bank of Western New York's (WNY) BackPack and School Pantry programs. The aim of these programs is to provide food for students deemed to be food insecure, because "many children who rely on free and/ or reduced-price school meals may be left without an adequate supply of food on the weekends or holidays when school is closed" (Food Bank of WNY, n.d., "BackPack Program," para. 1). The BackPack program is designed primarily for elementary school students and is a prepacked bag of food sufficient for breakfast and lunch or dinner, placed in students' backpacks to take home. Currently, the BackPack Program provides meals to 1,540 students in 22 BPS elementary schools (E. Burgher, personal communication, 0 ctober 3, 2017). On the other hand, a recent addition to the food bank's efforts to support food-insecure high school students is the School Pantry Program. As of O ctober 2017, it had been implemented at two BPS high schools, but an expansion was planned during the 2017-2018 year (Food Bank of WNY, n.d.; E. Burgher, personal communication, O ctober 3 , 2017). The main difference between the School Pantry Program and the BackPack Program is that the pantry is intended for older students who are able to "shop" in the pantry for food to bring home for themselves and their siblings. The majority of food given to students, while following guidelines recommended by food bank nutritionists, is preprocessed. Students rarely are provided with or have access to healthier, fresh food. Most food provided through these programs is donated by large retailers, such as Wal-Mart, rather than sourced from local producers.

While the BackPack and School Pantry 
programs try to remedy many of the social injustices stemming from an inequitable food system, they still lack characteristics of a just transition. Specifically, students' choices of food that they receive, particularly elementary students in the BackPack Program, are limited. These bags are prepacked and placed in the students' backpacks to take home, constraining the potential for culturally relevant food. The food options inside the bags are dependent on what has been donated to the food bank. Selections available in the school pantries are also dependent on donations. There is a slightly wider and more diverse variety of food staples available, offering students some culturally relevant choices. The limited choices are a small step toward democratization, which could be more fully actualized with choice across grade levels and through deliberative processes. Still, since donations are from big-box retailers, power is neither decentralized nor redistributed.

There is potential for a just transition in these programs. The Food Bank of WNY is trying to devise ways to source more food, particularly produce, from local farmers. While the funds paying for this produce would still be donated by large retailers, such an initiative would enable the food bank to help improve the quality of food provided to students and redistribute food system purchasing power to support local farmers. This initiative would reflect several elements of a just transition, including decentralizing, democratizing, diversifying economic activity, and redistributing resources. In addition, sourcing fresh produce from local farmers would decrease consumption of preprocessed food, a clear improvement for the most vulnerable students. This would also reduce the amount of packaging used and the distance that food must travel, reducing the negative ecological impacts of the food given to students.

Unfortunately, other than the indirect ecological benefits of reducing preprocessed foods, the food bank has no further environmental activities planned for the BackPack and School Pantry programs, which greatly inhibits a just transition. Without comprehensive efforts, these programs serve as stopgap measures that have the ability to reach vulnerable populations at particular moments, but lack the ability to address root causes of social and environmental injustices related to food insecurity.

$\mathrm{N}$ ew programs: F arm to School Beginning in 2015, the Farm to School Program (F2S) was piloted in 12 schools. In the 2017-2018 school year, F2S was rolled out to the rest of the district's schools. The F2S program aims to "[support] regional farmers by increasing the procurement of local farm goods, provid[e] BPS students with access to nutritious locally sourced farm goods and educat[e] the school community about F2S" (BPS Farm to School Coordinating Committee, 2015, p. 3). The F2S program contributes to the local economy and brings fresh fruits and vegetables into BPS. However, this new program is still small in the overall budget, and few menu items contain local products. There is a redistribution of only a small portion of the power and resources across the scaled federal-to-local school food systems.

In order to achieve F2S goals, program coordinators created the Harvest of the Month, which promotes fresh, seasonal produce every month. The Harvest of the Month food is served as a meal component four times per month and is featured on posters and promoted via flyers that explain how the food is grown and what it can be used for, including a simple recipe or two for students and parents to make at home (Figure 1). The commencement of the F2S program initiated an immediate increase in the amount of local produce purchased and served by BPS. In addition, contrary to initial concerns, no significant spending increases have resulted from this shift in procurement. The F2S program has substantial potential to continue toward a just transition.

An important factor influencing the success of the BPS F2S program is student acceptance of new, healthier menu items. As many students have not previously been exposed to the fresh fruits and vegetables introduced by F2S, program coordinators implemented Taste Test Thursdays. Students are invited to sample and vote to add, or to not add, potential recipes to school menus. Voting allows students not only to have a voice in determining new recipes, but also encourages them to try new foods that they might not 

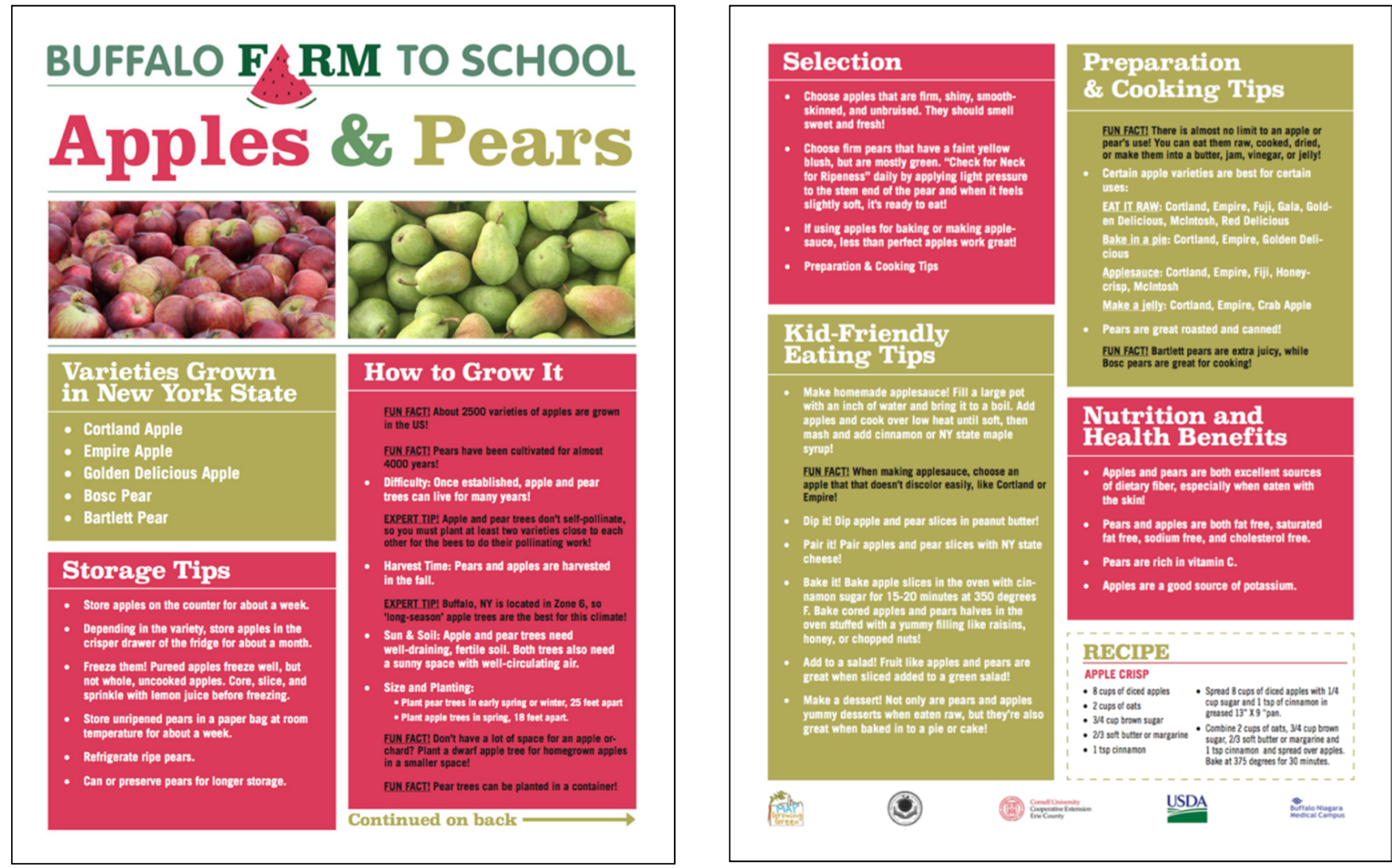

Source: Buffalo Farm to School website: http:// buffalofarmtoschool.org/

otherwise eat. D ue to its use of democratic decision-making processes, Taste Test Thursdays is a program within a program that represents a just transition. This initiative cements the value of distributed, democratic participation in the decision-making process in efforts to improve school food. Through the voting process, Taste Test Thursdays contribute to the decentralization and redistribution of power by allowing those outside of the Food Services D epartment to contribute to decisions about what is purchased and served. School food service staff also get to participate in this process by administering the voting, which broadens participation in school food decisions, engaging students with district administrators.

The F2S program has overcome numerous barriers and has experienced significant successes thus far. It has generated increased access to fresh, healthy food for BPS students, opened up a new and stable market to local farmers, contributed to a decrease in the amount of preprocessed food that is served to students, and increased democratic participation in decision-making.

Transitioning toward justio: Buffalo School G ardens The goals of the Buffalo School Gardens is "to support the development of sustainable school gardens that facilitate academic growth, community building, and healthy lifestyles" (Buffalo School Gardens, n.d., para. 1). As Robert, Stapleton, and Wilder (2017) write, "D espite limited resources and a constrained policy environment as well as the newness of outside, interdisciplinary, experiential learning to city schools, enthusiasm for school gardens continues to spread throughout the district" (p. 1). As of the 2017-2018 academic year, there are 26 elementary, middle, and high schools in the BPS system that have official gardens. All were initiated through the grassroots efforts of parents, students, teachers, and community members.

Buffalo School Gardens is a bit of an outlier within the school food system for several reasons. 
The school gardens are a grassroots movement bringing together parents, students, teachers, and administrators (both school-based and districtbased). Underlying the stated goal is a movement to incorporate hands-on, place-based, and inquirydriven experiences with the food system. Students with their teachers, parents, and many other school and community members grow plants, engage in indoor and outdoor learning, and learn and actively participate in the urban environment in which they live. In addition, the gardens are open to the public to foster community-school relationships. The creation and maintenance of school gardens are not only instigated, but controlled, by the school and community together. Power is decentralized and negotiated through democratic decisionmaking practices about what is grown, where, how, by whom. Finally, recognizing that produce from the school gardens depends on soil health and other environmental resources, school gardens provide a critical lens through which garden participants learn of the importance and interconnections of social and ecological justice.

As a result of bussing, there is a severe disconnect between the populations of schools and the communities that surround them. In less than five years, however, 26 gardens have been created and are maintained at elementary, middle, and high schools, illustrating that the goals of the initial organizers are shared and represent a watershed movement that brings schools and communities together despite significant differences and disconnects between school food system actors. The Buffalo School G ardens are a strong example of a just transition-centered school food program through equitable and decentralized distributions of resources and power. The creation and maintenance of school gardens embody the active and intentional decentralization and redistribution of power and resources from the hands of a few corporations into those of the community. The gardens undermine the corporate structure of the national and community food system by engaging collectively with the environment and each other to reimagine and learn to develop an alternative, locally and democratically controlled (school) food system.

However, enthusiasm, especially in the initial stages, does not always translate to continued and sustainable (school and community) involvement. This is the current challenge for Buffalo School Gardens: how to maintain participation in the projects. Many of the gardens are located in areas that are not easily accessible to community residents, which has significantly limited neighborhood engagement. $\mathrm{G}$ arden leadership also changes as parents, who are instrumental in the creation and maintenance of school gardens, often cease involvement when their children leave the garden's school, or as teachers and administrators retire or transfer to different schools. While new parents and teachers sometimes take over, this is not always the case; sustainability is a constant concem. Additionally, BPS Community Schools (schools that serve as educational centers connecting families and communities in such a way as to foster student learning, parent engagement, and healthier students and communities) have recently been mandated to have school gardens. This presents a curious challenge to a grassroots movement that grew rhizomatically from school to school. Specifically, this new formal program of the school district poses very real challenges to the key elements of democratization, decentralization, and distributed power, which were the spirit of the movement (Robert Stapleton, \& Wilder, 2017). Still, the gardens embody many of the just transition strategies by incorporating ecological and agricultural education, cultivating community, increasing the students' and communities' access to and choices of fresh food, and offering an example of how to disrupt dependence on preprocessed foods.

\section{Conclusions}

The study presented here reflects a snapshot of a dynamic system. It is particularly important to point out that we wrote this manuscript at the beginning of a school year with a new U.S. president in the Oval Office. The previous administration had prioritized health and healthy eating, especially childhood nutrition, by promoting scientifically grounded improvements in school food and even encouragement of school gardens (National School Lunch Program and School Breakfast Program, 2010). In the first months of 
the new administration, it appears that those are no longer priorities (Child Nutrition Program, 2017). The halt to the transition toward healthier school food has not affected the local food system yet because school food procurement is arranged one year in advance. Further research would need to take into account a longer policy timeline to capture the coming transition within the national policy context.

This case study explored how a public school food system engages in and builds toward incorporating elements of a just transition. We used content analysis to examine five programs in the BPS's food system for five just transition strategies during the 2017-2018 school year. We situated the school food system within the larger community food system making strides toward a just food transition. The federal food system in which both the school and community system are embedded will most certainly affect efforts to implement a just transition. This aspect makes the study all the more important because it serves as a marker of a just transition in a process that may be affected by public policy decisions far beyond the local level.

All five programs possess strategies of a just transition. However, there are significant ways to build on the strides they have already made. One particularly urgent missing component is the need to acknowledge the intimate link - the symbiosis even - of human and ecological justice. While many of the programs have begun to address social injustices within the school food system, ecological health has been overlooked. As a food system is inherently social and ecological, both components need to be addressed if comprehensive reform and systemic change are to be realized. Thus, school districts and local governments more broadly can improve ecological justice by creating policies that consider environmental sustainability as an integral part of a food system. F2S programs are well poised to act as a starting point for this transition.

Schools also can serve as places of intervention. Not only does school food purchasing possess power in the current food system and thus retain the ability to shift how food is produced, but schools can introduce the concept to students that a just transition in the food system is possible. In addition, schools can offer an educational platform instructing students in how food transformations occur, why they are important, and how food demonstrates the complex interdependence of social and ecological systems. As the future is reliant on both ecological and social sustainability, it is essential that younger generations be part of any transition process. Finally, implementing a just transition in school food will contribute to decreasing food insecurity among students, thus achieving a vital step toward a just transition.

Several other significant changes would be necessary to enact more just social and ecological transitions in school food systems. First, although we do not discuss curriculum in this paper, integrating learning about the food system is an important aspect of creating and sustaining a just food system. The curriculum is centralized and is enforced by states and local district administrations. This enforcement occurs via state testing administered throughout elementary and secondary grades. We do not include curriculum in the data because it is not local per se. Future studies can and should examine curriculum for and as opportunities to educate for a just transition (see, for example, Y amashita \& Robinson, 2016). We suggest that student learning about and engaging in school food systems serve as important transformational sites within community food systems, where young people learn about food production (and its links to human and ecological health and sustainability), food (in)security, and food connections.

As a second point, there are programs focused on food systems that are not administered or funded by the public school system that we suggest should be integrated into student learning and into school food system policies and regional planning. Recognizing the uneven distribution of food access throughout the city, many organizations run programs to bring healthy, culturally appropriate food to those who need it most. While such initiatives target numerous facets of the food system, perhaps the most active have been those addressing food justice among students, both by employing youth on urban farms and by engaging youth in policy activism and campaign organizing. The study included here does not include these programs or organizations. However, it is important to 
acknowledge the impact they have on the system (Raja, Picard, Baek, \& D elgado, 2014).

While there are just transition elements in process in these five programs, more transition can and should occur. For example, in addition to promoting fresh food from local farmers, districts could encourage procurement preferences based on pro-environmental production methods, and decreased consumption of the packaging materials needed for preprocessed foods. In doing so, not only would districts encourage the decentralization and redistribution of power back into local hands, but they also would reduce the negative ecological consequences of food production. Addressing both social and ecological issues regarding food production and consumption would bring districts much closer to successfully implementing a just transition through school food. There are strong examples from across the country of school districts that, despite being embedded in the federal school food budgeting and procurement chains, have made significant strides toward a just transition. Other school districts can turn to these for ideas and encouragement- from $\mathrm{O}$ akland, California, to Burlington, Vermont (see Hamerschlag \& KrausPolk, 2017, and D avis, Hudson, \& the Burlington School Food Project, 2011, respectively).

We draw attention to the promise of a just transition framework to provide a structure for considering the ways in which complex and dynamic systems interact and can be modified toward justice-oriented purposes. This work is meaningful to us from the standpoint of engaging as scholar-activists. O ur analysis of the local school food system provides us with an opportunity to engage meaningfully within the food system as we can put forward focused and structured goals in conversation and collaboration with local stakeholders. O thers might utilize the just transition framework and analysis similarly, and we suggest that the framework's potential can be both broadened - to include the ways in which multiple systems interact (e.g., food, energy, and transportation systems), or hyperfocused- to selectively explore one aspect of a transition (e.g., the just nature of interactions within decentralizing decision-making practices).

There is a need for local policymakers also to be invested and held accountable for the just transition of the food system. Instances of foodrelated social injustice are not unique to food at school, nor can inequities caused by school food be addressed without connecting them to the larger food system of which they are a part. Injustices within school food systems are not limited to lowincome school districts. Just transitions have potential even in upper-income districts to meaningfully and sustainably affect lives, ecologies, and economies. School food is only a component within a much larger, soil-to-soil system that enables and manages the processes of production, distribution, consumption, and disposal of food, which are driven by environmental resources, technologies, cultural norms, and governance structures, policies, and laws. School food both affects and is affected by all elements of the food system. Therefore, the complexity encompassed within efforts to comprehensively improve school food demands that all actors within and facets of a community food system undergo a just transition.

\section{Acknowledgments}

The authors would like to thank Sam Magavern, executive director of the Partnership for the Public Good, for his helpful comments on a draft of this article.

\section{References}

Akom, A. (2011). Eco-apartheid: Linking environmental health to educational outcomes. T eachers C ollege Record, 113(4), 831-859. Retrieved from ERIC website: https:/ / eric.ed.gov/ ?id=EJ927096

Block, D. R., Chávez, N., Allen, E., \& Ramirez, D . (2012). Food sovereignty, urban food access, and food activism: Contemplating the connections through examples from Chicago. A griaulture and $\mathrm{H}$ uman V alues, 29(2), 203-215. https:/ / doi.org/ 10.1007/ s10460-011-9336-8

Buffalo Public School Farm to School Coordinating Committee. (2015). Buffalo Public School D istric: Farm to school implementation plan. Retrieved from https:/ fns-prod.azureedge.net/ sites/ default/ files/ f2s/2015BuffaloAction $\underline{\text { Plan.pdf }}$ 
Journal of Agriculture, Food Systems, and Community Development

ISSN: 2152-0801 online

https:/ / www.foodsystemsjournal.org

Buffalo Billion. (n.d.). About Buffalo Billion. Retrieved on December 10, 2017, from

https:// buffalobillion.ny.gov/ about-buffalo-billion

Buffalo School Gardens. (n.d.). Home page. Retrieved on October 11, 2017, from http:// www.buffaloschoolgardens.com

Bundy, D ., Burbano, C., Grosh, M., G elli, A., Jukes, M., \& D rake, L. (2009). Rethinking school feeding: Social safety nets, child development, and the education sector. Washington, D.C.: The World Bank and World Food Program. http:/ / hdl.handle.net/ 10986/ 2634

Child Nutrition Program: Flexibilities for Milk, Whole G rains, and Sodium Requirements, 82 FR 56703 C.F.R. (2017).

Connelly, C. (2008). Brownfield cleanup and development in Buffalo, N ew Y ork [Factsheet]. Retrieved from https:// ppgbuffalo.org/ files/ documents/ economic development/ policies and programs/ economicdevelopmentbrownfields.pdf

Cooper, S. B., Bandelow, S., \& Nevill, M. E. (2011). Breakfast consumption and cognitive function in adolescent schoolchildren. Physiology \& B ehavior, 103(5), 431-439. https:/ / doi.org/ 10.1016/ j.physbeh.2011.03.018

Davis, D., Hudson, D., \& Members of the Burlington School Food Project. (2011). Going local: Burlington, Vermont's Farm-to-School Program. In S. A. Robert \& M. B. Weaver-Hightower (Eds.), School food politics: The complex eology of hunger and feeding in schools around the world (pp. 162-182). New York: Peter Lang.

Eakin, H., \& Luers, A. L. (2006). A ssessing the vulnerability of social-environmental systems. The A nnual Review of E nvironment and Resouros, 31, 365-394. https:/ / doi.org/ 10.1146/ annurev.energy.30.050504.144352

Ericksen, P., Stewart, B., Dixon, J., Barling, D ., Loring, P., Anderson, M., \& Ingram, J. (2012). The value of a food system approach. In J. Ingram, P. Ericksen, \& D . Liverman (Eds.), F ood Security and G lobal E nvironmental Change (pp. 25-45). Oxon, UK, and New York: Taylor \& Francis.

Erie County D epartment of Health. (2017). E rie C ounty N ew Y ork C ommunity H ealth A ssessment 2017-2019. Retrieved from http:/ / www2.erie.gov/ health/ sites/ www2.erie.gov.health/ files/ uploads/pdfs/ cha.pdf

Faught, E. L., Williams, P. L., Willows, N. D., Asbridge, M., \& Veugelers, P. J. (2017). The association between food insecurity and academic achievement in Canadian school-aged children. Public $\mathrm{H}$ ealth N utrition, 20(15), 2778-2785. https:/ / doi.org/ 10.1017/ S1368980017001562

Florence, M. D., A sbridge, M., \& Veugelers, P. J. (2008). Diet quality and academic performance. Journal of School $\mathrm{H}$ ealth, 78(4), 209-215. https:// doi.org/ 10.1111/ j.1746-1561.2008.00288.x

Food and Agriculture O rganization of the United Nations, International Fund for Agricultural Development, \& World Food Program. (2015). The state of food insecurity in the world 2015. Retrieved from http:// www.fao.org/ 3/ a-i4646e.pdf

Food Bank of Westem New York. (n.d.). Food for kids. Retrieved from https:/ / www.foodbankwny.org/ about-us/ howthe-food-bank-works/ programs/ food-for-kids/

Food Equity Ideas Lab Workshop Steering Committee. (2017). F ood E quity W orking D efinition: D raft for Ideas L ab [Microsoft Word file]. Buffalo, New York: University at Buffalo Food Equity Ideas Lab.

Fraser, N. (1997). Justice interruptus: C ritical reflections on the "postsocialist" condition. New Y ork: Routledge.

Gibson-Graham, J. K., \& Miller, E. (2015). Economy as ecological livelihood. In K. Gibson, D. Bird Rose, \& R. Fincher (Eds.), M anifesto for L iving in the A nthropocene (pp. 7-16). Brooklyn, NY: Punctum Books.

Gilbert, J. (2018a). Good Food Buffalo Policy Brief. Retrieved from Buffalo Commons: https:/ / ppgbuffalo.org/ buffalocommons/ library/p:1/ resource:good-food-buffalo-policy-brief/

Gilbert, J. (2018b). G ood food purchasing for the Buffalo Public Schools: L ocal eeonomies, nutrition, valued work force, environmental sustainability, and animal welfare. Buffalo, NY: Partnership for the Public Good. Retrieved from https:/ / ppgbuffalo.org/ files/documents/ education/good food purchasing_for the buffalo public schools.pdf

Gottlieb, R., \& Joshi, A. (2010). Food justiœ. Cambridge, MA: MIT Press.

Guthman, J. (2011). W eighing in: 0 besity, food justice, and the limits of capitalism. Berkeley: University of California Press.

Hamerschlag Kari \& K raus-Polk, J. (2017). Shrinking the carbon and water footprint of school food: A recipe for combating climate change. Washington, D .C.: Friends of the Earth. Retrieved from https:/ / foe.org/ resources/ shrinking-carbon-waterfootprint-school-food/

Hassanein, N. (2003). Practicing food democracy: A pragmatic politics of transformation. Journal of Rural Studies 19(1), 77-86. https:/ / doi.org/ 10.1016/ S0743-0167(02)00041-4 
Healy, N., \& Barry, J. (2017). Politicizing energy justice and energy system transitions: Fossil fuel divestment and a "just transition." E nergy Policy, 108, 451-459. https:/ / doi.org/ 10.1016/ j.enpol.2017.06.014

Jenkins, K., McCauley, D ., Heffron, R., Stephan, H., \& Rehner, R. (2016). Energy justice: A conceptual review. E nergy Research \& Social Scienœ, 11, 174-182. https:/ / doi.org/ 10.1016/ j.erss.2015.10.004

Kohlbacher, F. (2006). The use of qualitative content analysis in case study research. Forum: Q ualitative Social Research, 7(1), Art. 21. http:// dx.doi.org/ 10.17169/ fqs-7.1.75

Krippendorff, K. (2013). C ontent analysis: A $n$ introduction to its methodology (Third ed.). Los Angeles: SAGE Publications.

Krolikowski, A., \& Magavern, S. (2017). W orking towards equality, updated: Raœ, employment, and public transportation in E rie County. Buffalo, NY: Partnership for the Public Good. Retrieved from https:/ / ppgbuffalo.org/ files/ documents/ working toward equalityfinal.pdf

Levine, S. (2010). School lunch politics: The surprising history of America's favorite welfare program. Princeton, NJ: Princeton University Press.

Levkoe, C. Z. (2011). Towards a transformative food politics. L ocal E nvironment, 16(7), 687-705. https:// doi.org/ 10.1080/ 13549839.2011.592182

Levkoe, C. Z., \& Wakefield, S. (2011). The Community Food Centre: Creating space for a just, sustainable, and healthy food system. Journal of A griaulture, Food Systems, and Community D evelopment, 2(1), 249-268. https:/ / doi.org/ 10.5304/ jafscd.2011.021.012

Magavern, S. (2016). W ork ing toward equality: E mployment and raœ in Buffalo. Buffalo, NY: Partnership for the Public Good. Retrieved from https:/ / ppgbuffalo.org/ files/documents/ equality civil_rights/ race/ equalitycivilrightsworking toward equity.pdf

Meyers, A. F., Sampson, A. E., Weitzman, M., Rogers, B. L., \& Kayne, H. (1989). School Breakfast Program and school performance. A merican Journal of D iseases of Children, 143(10), 1234-1239. https:/ / doi.org/ 10.1001/ archpedi.1989.02150220142035

Miller Hesed, C. D ., \& O stergren, D . M. (2017). Promoting climate justice in high-income countries: Lessons from African American communities on the Chesapeake Bay. Climatic C hange, 143(1-2), 185- 200. https:// doi.org/ 10.1007/ s10584-017-1982-4

Morgan, K., \& Sonnino, R. (2013). The school food revolution: Public food and the challenge of sustainable development. London: Routledge. https:// doi.org/ 10.4324/ 9781849773256

Movement Generation. (n.d.). From banks and tanks to coperation and caring: A strategic framework for a just transition. Retrieved from http:/ / www.movementgeneration.org

Murphy, J. M., Pagano, M. E., Nachmani, J., Sperling, P., Kane, S., \& Kleinman, R. E. (1998). The relationship of school breakfast to psychosocial and academic functioning: Cross-sectional and longitudinal observations in an inner-city school sample. A rchives of Pediatrics \& A dolescent Medicine, 152(9), 899-907. Retrieved from https:/ / jamanetwork.com/ journals/ jamapediatrics/ fullarticle/ 189855

National School Lunch Program and School Breakfast Program: Nutrition Standards for All Foods Sold in School as Required by the Healthy, Hunger-Free Kids Act of 2010, 7 C.F.R 210; 7 C.F.R. 220 C.F.R. (2010).

Nutrition Standards in the National School Lunch and School Breakfast Programs; Final Rule 77 C.F.R. § 210 \& 220 (2012).

Partnership for the Public Good. (2018a). Immigrants, refugees, and languages spok en in Buffalo. Retrieved from https:// ppgbuffalo.org/ files/ documents/immigration buffalo brief final.pdf

Partnership for the Public Good. (2018b). Poverty in Buffalo-N iagara. Retrieved from https:// ppgbuffalo.org/ files/documents/ poverty_low_wage work income inequality/ general/ poverty_2014.pdf

Poppendieck, J. (2010). Free for all: Fixing school food in America. Berkeley and Los Angeles: University of California Press.

Raja, S., Clark, J., Hodgson, K., \& Freedgood, J. (2017). Call for papers on local government. Retrieved on November 15, 2017, from https:/ / www.foodsystemsjournal.org/ index.php/ fsj/ call-for-papers-govt 
Raja, S., Hall, J., Norton, T., Gooch, P., Raj, S., Hawes, T., \& Whittaker, J. (2014). G rowing together: E nsuring healthy food, viable farms, and a prosperous Buffalo $\mathrm{N}$ iagara. Retrieved from https:/ / growingfoodconnections.org/ wpcontent/ uploads/ sites/3/ 2018/07/39 Raja Hall etal 2014 GrowingTogetherEnsuringhealthyfood...BuffaloNiaga $\underline{\text { ra UB.pdf }}$

Raja, S., Ma, C., \& Yadav, P. (2008). Beyond food deserts: measuring and mapping racial disparities in neighborhood food environments. Journal of Planning E ducation and Research, 27(4), 469-482. https:/ / doi.org/ 10.1177/ 0739456X 08317461

Raja, S., Picard, D ., Baek, S., \& D elgado, C. (2014). Rustbelt radicalism: A decade of food systems planning in Buffalo, New York (USA). Journal of A griculture, F ood Systems, and Community D evelopment, 4(4), 173-189. https:// doi.org/ 10.5304/ jafscd.2014.044.015

Reinharz, S., \& D avidman, L. (1992). Feminist methods in social research. New York: Oxford University Press.

Robert, S. A., Stapleton, K. S., \& Wilder, G . (2017). H ow does your garden grow? A collaboration of the Buffalo School G ardens, $\mathrm{G}$ rassroots $\mathrm{G}$ ardens of Buffalo, and the U B G raduate School of $\mathrm{E}$ ducation. Unpublished Fellowship Proposal, Faculty in Residence.

Robert, S. A. \& Weaver-Hightower, M. (2011). School food politics: The complex ecology of hunger and feeding in schools around the world. New York: Peter Lang.

Ruis, A. R. (2017). Eating to learn, learning to eat: The origins of school lunch in the United States. New Brunswick: NJ: Rutgers University Press. https:// doi.org/ 10.2307/j.ctt1q1cr7t

Stake, R. (1995). The art of the case study. Thousand Oaks, CA: SAGE Publications.

Wesnes, K. A., Pincock, C., Richardson, D., Helm, G., \& Hails, S. (2003). Breakfast reduces declines in attention and memory over the morning in schoolchildren. A ppetite, 41(3), 329-331. https:/ / doi.org/ 10.1016/ j.appet.2003.08.009

World Food Programme. (2017). H ow school meals ontribute to the sustainable development goals: A collection of evidence. Rome: World Food Programme. https:/ / docs.wfp.org/ api/ documents/ b91da1b2fa2344f6b9f4bad1cfbca40a/ download

Yamashita, L., \& Robinson, D . (2016). Making visible the people who feed us: Educating for critical food literacy through multicultural texts. Journal of A griculture, Food Systems, and C ommunity D evelopment, 6(2), 269-281. https:// doi.org/ 10.5304/ jafscd.2016.062.011

Yin, R. K. (2003). Case study research and applications: D esign and methods (6th ed.). Thousand Oaks, CA: SAGE Publications. 